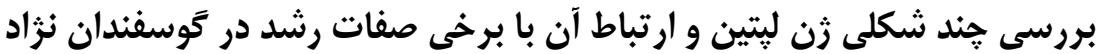 لرى بختيارى و آميخته لرى بنتين باطيارى - افثنارى

\author{
على قاضى خانى شاد و محمد كاظم شريفى شور ابى
}

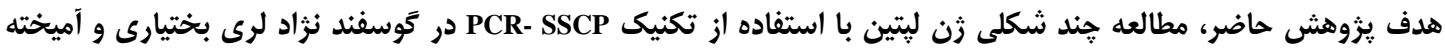

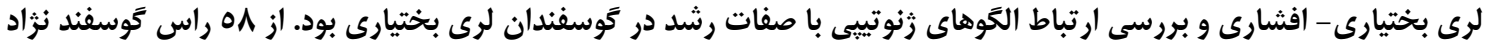

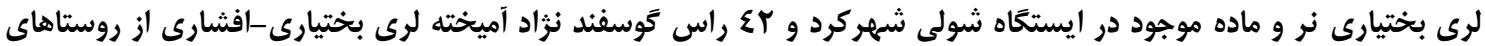

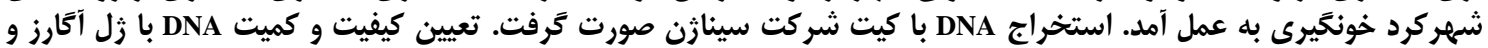

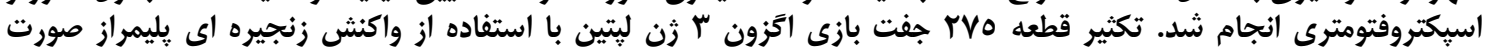

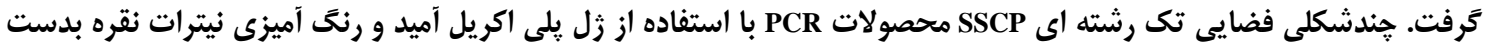

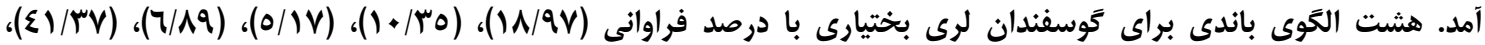

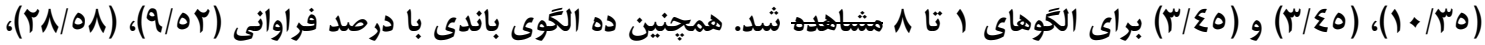

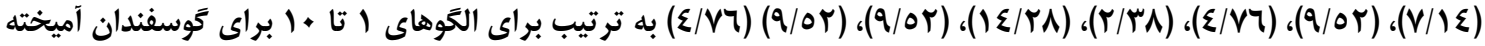

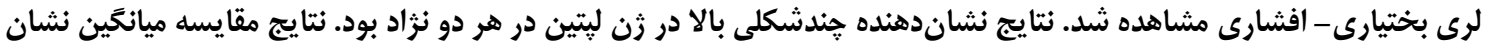

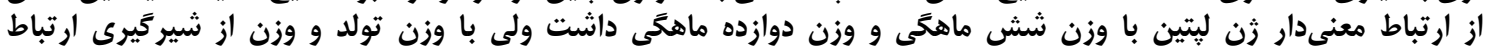

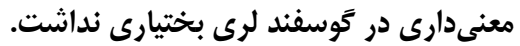

وازههاى كليدى: زن لِّتين، كَوسفند لرى بختيارى، صفات رشد و PCR- SSCP

تنظيم مى كند. كشف لِتين موجب ايجاد زمينههاى تحقيقاتى

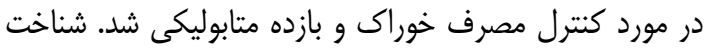

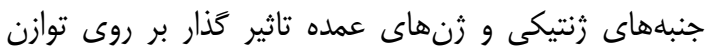

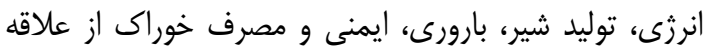

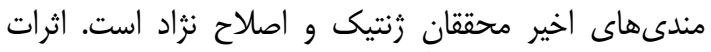

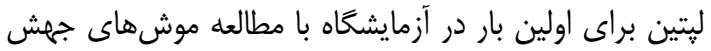

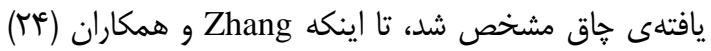

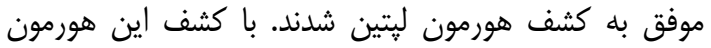

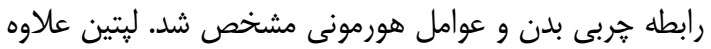

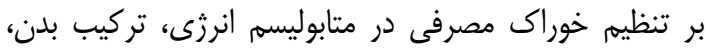

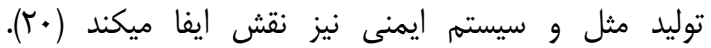

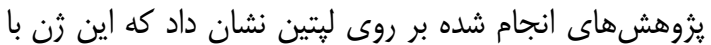

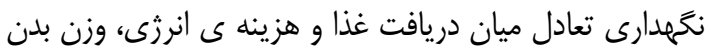

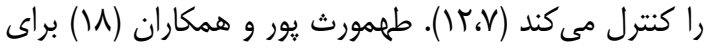

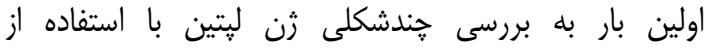

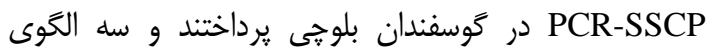

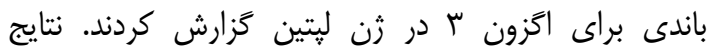

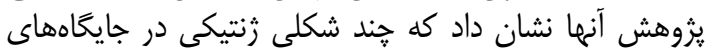

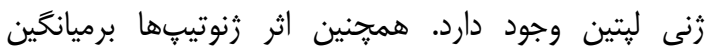

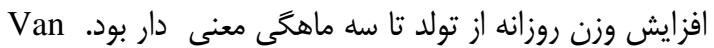

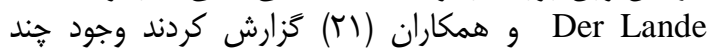

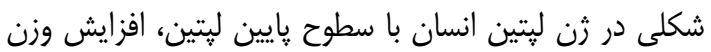

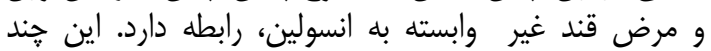

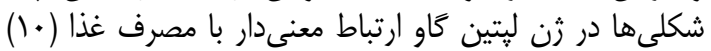

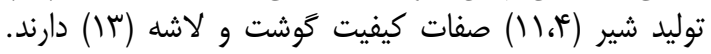

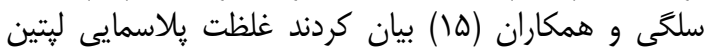

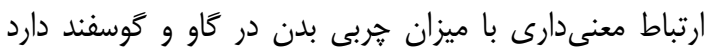

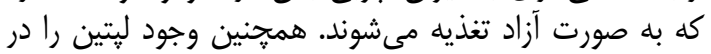

\section{مقدمه}

در بين دامهاى اهلى، گَوسفند بيشترين تنوع را دارد، به داه

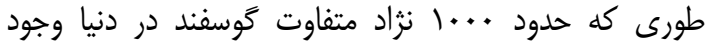

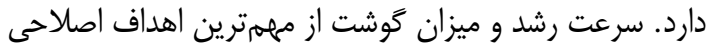

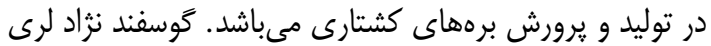

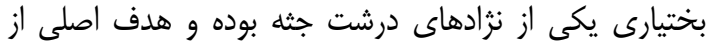

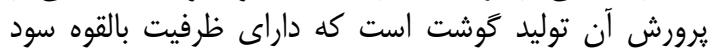

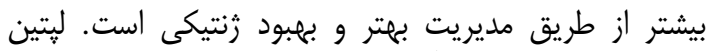

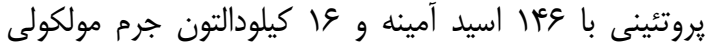

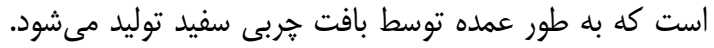

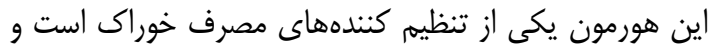

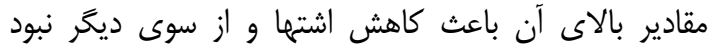

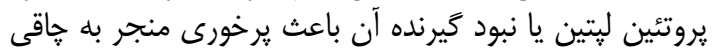

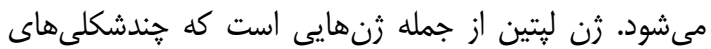

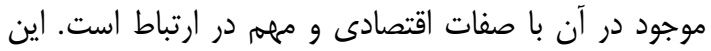

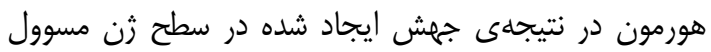

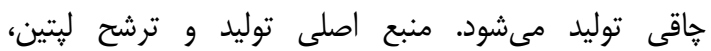

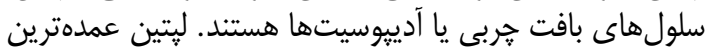

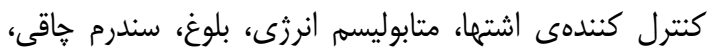

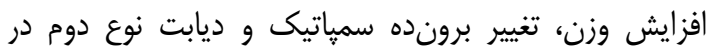

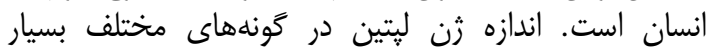

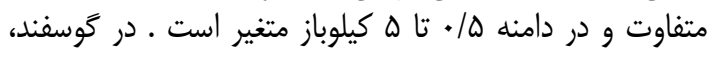

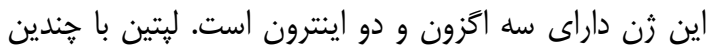

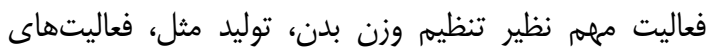

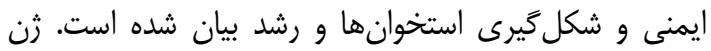

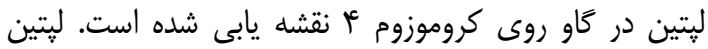

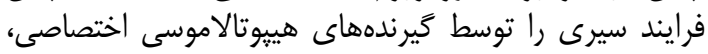

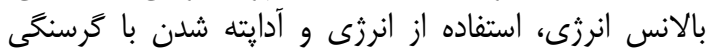




\section{تعيين كميت و كيفيت DNA}

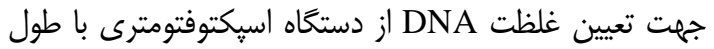

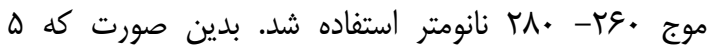

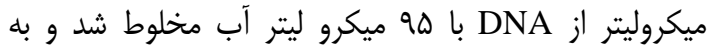

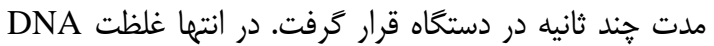

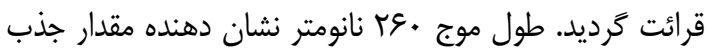

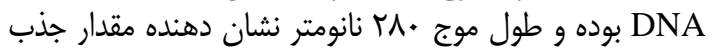

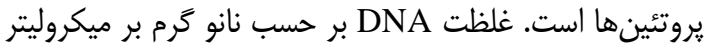

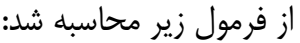

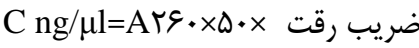

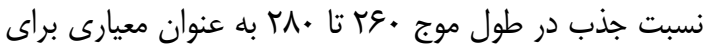

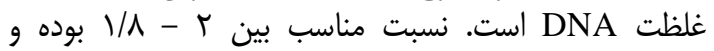

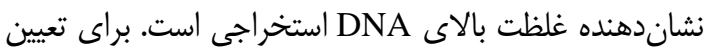
كيفيت DNA زنومى از زل آكَارز إد درصد استفاده شد. مقدار

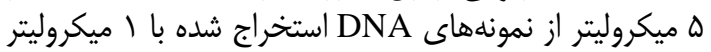

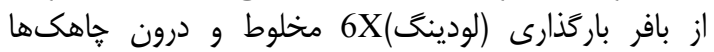

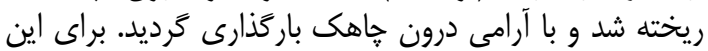

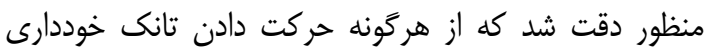

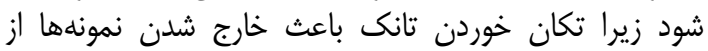

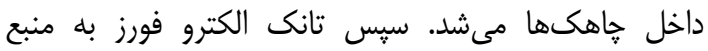

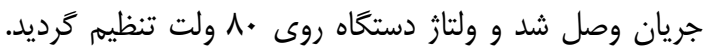

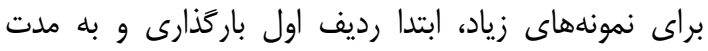

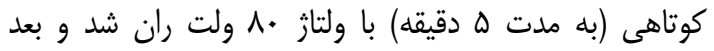

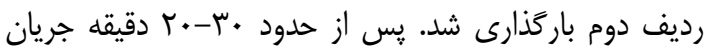

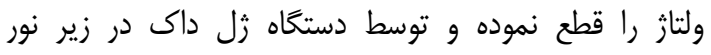

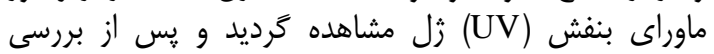

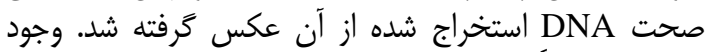

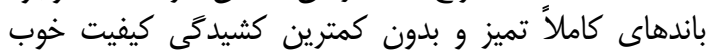

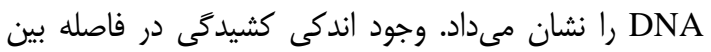

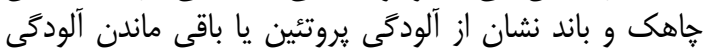

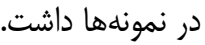

Pراحل انجام دراشت

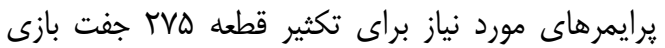
اخزون سوم زن لِّين به صورت زير بودندي

\section{F: 5'-GCT CCA CCC TCT CCT GAG TTT GTC C-3}

\section{R: 5-TGT CCT GTA GAG ACC CCT GTA GCC} G-3

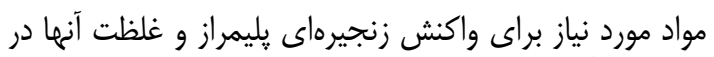

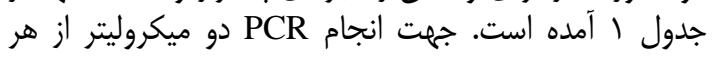

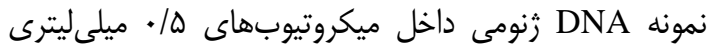

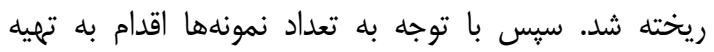

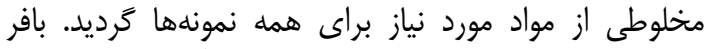

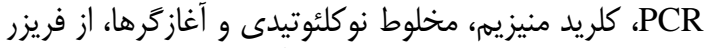

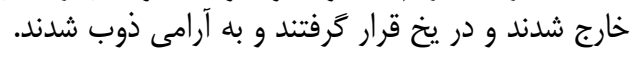

هييوتالاموس و هيبوفيز يِيشين كوسفند كزارش كردند. لِّتين

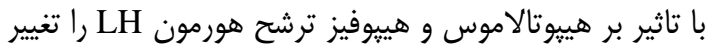

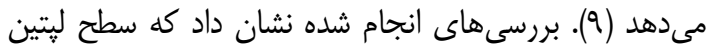

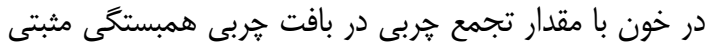

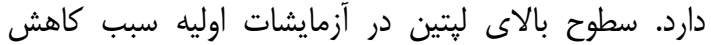

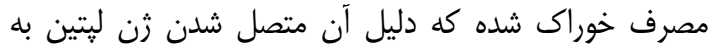

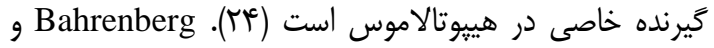

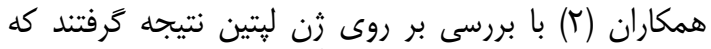

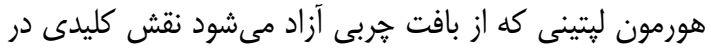

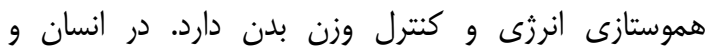

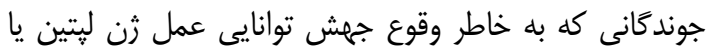

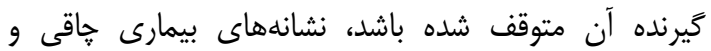

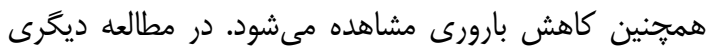

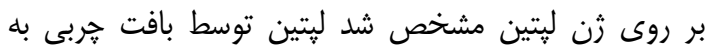

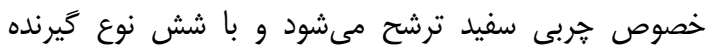

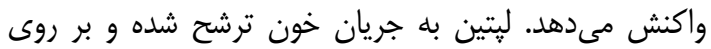

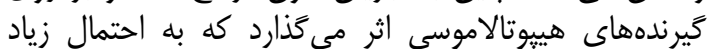

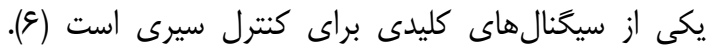

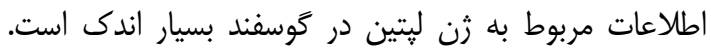

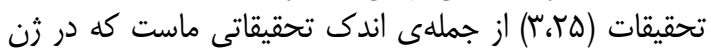

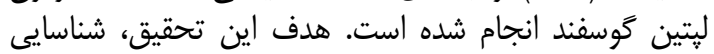

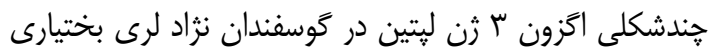

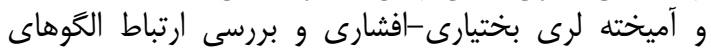

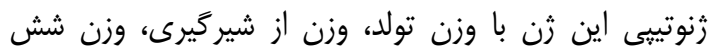
ماهكى و وزن دوازده ماهكى در كوسفندان نزاد لرى بخى بختيارى

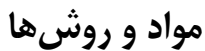 دامهاى مورد استفاده}

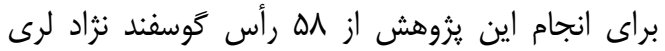

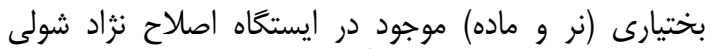

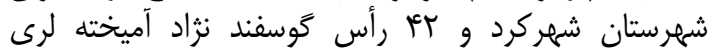

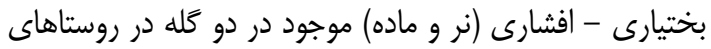

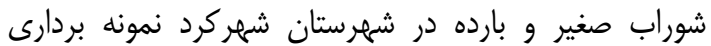

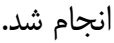

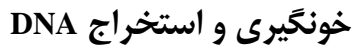

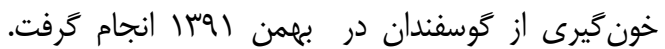

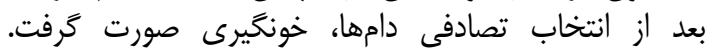

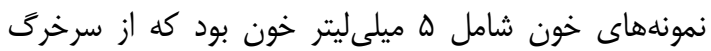

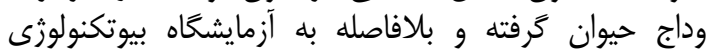

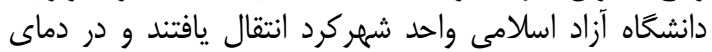

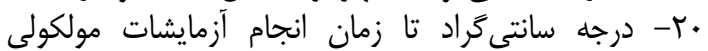

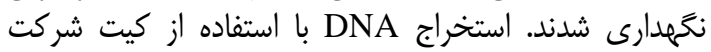
سيناثن ايران (DNPTM Kit) طبق دستورالعمل كيت مذكور

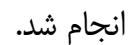


Table 1. The required materials for polymerase chain reaction

جدول ا- مواد مورد نياز براى واكنش زنجيرهاى يليمراز

\begin{tabular}{|c|c|c|c|}
\hline غلظت يا مقدار مورد نياز & حجم مورد نياز به ازاى يك نمونه & غلظت در محلول پايه & ماده \\
\hline • •ه نانو كرم & r ميكرو ليتر & ف א نانوگرم در ميكرو ليتر & $\overline{\mathrm{DNA}}$ \\
\hline $1 \mathrm{X}$ & م/ه ميكرو ليتر & $1 \cdot x$ & بافر PCR \\
\hline ه/1/ ميلى مولار & ا ميكرو ليتر & هT ميلى مولار & كلريد منيزيم \\
\hline آ/ • ميلى مولار & |ه/• ميكرو ليتر & . & مخلوطنو كلئوتيدى \\
\hline •ا ريكو مول. & ا ميكرو ليتر & •ا ييكو مول در ميكرو ليتر & آغازكر رفت \\
\hline • 1 ي ييكو مول & ا 1 & • إي ي ايكو مول در ميكرو ليتر & آغازمر برَشت \\
\hline 年 & 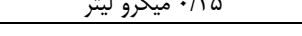 & ف واحد در ميحرو ليتر & 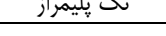 \\
\hline
\end{tabular}

Dا ميكرو ليتر كشيده و به ميكروتيوبهاى ها ه + ميلىليترى

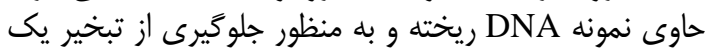

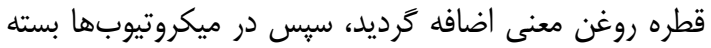
شد و بلافاصله نمونهها در دستى إناه

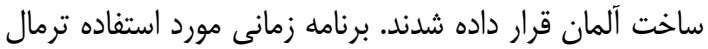

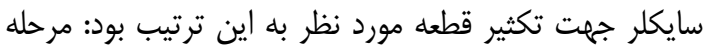

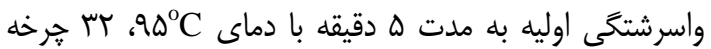

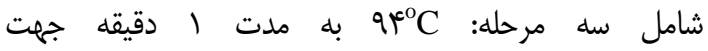
واسرشت سازى ثانويه،

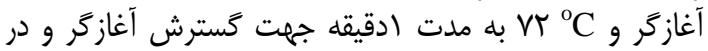

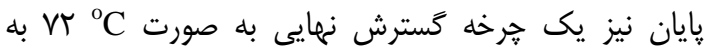
مدته دقيقه در نظر گرفته شد.

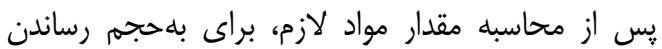

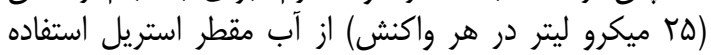

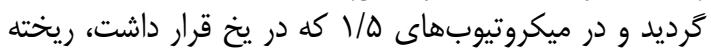

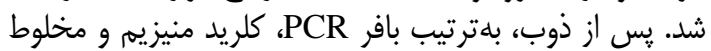

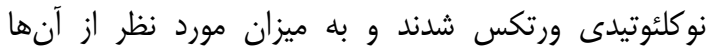

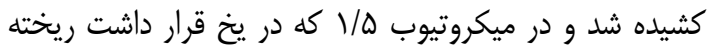

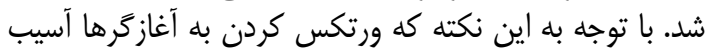

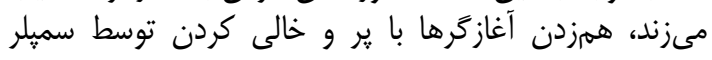

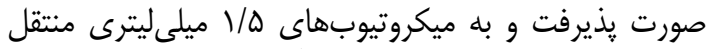

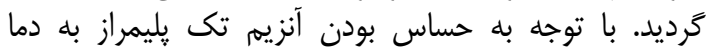

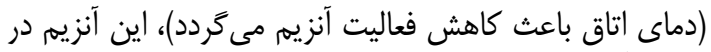

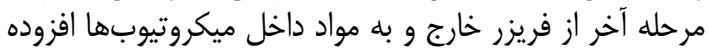

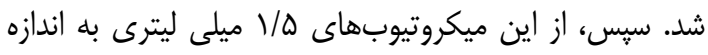

جدول r- برنامهى زمانى، دمايى و تعداد جرخه واكنش زنجيرهاى يليمراز

Table 2. Thermal cycle program for polymerase chain reaction

\begin{tabular}{|c|c|c|c|}
\hline تعداد קرخه & زمان & دما (سانتى گر اد) & مرحله \\
\hline \multirow{5}{*}{ r r קرخه } & 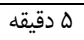 & 90 & واسرشت سازى اوليه \\
\hline & ا دقيقه & 94 & واسرشت سازى ثانويه \\
\hline & ا دقيقه & $\Delta 9$ & اتصال آغازگر \\
\hline & ا 1 دقيقه & VT & كَسترش آغازگر \\
\hline & 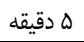 & VT & كسترش نهايى \\
\hline
\end{tabular}

شدهاند مخلوط كرده، به مدت •1 دقيقه و با دماى هو درجه

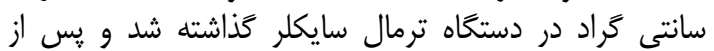

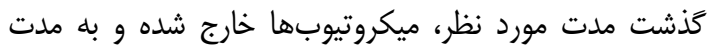

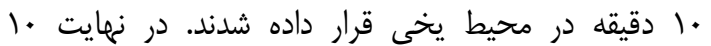

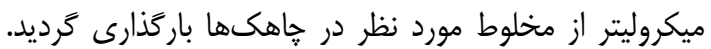

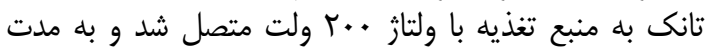

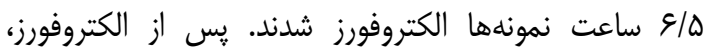

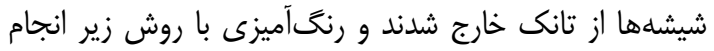

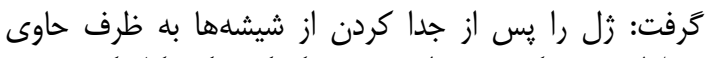

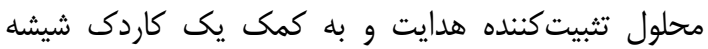

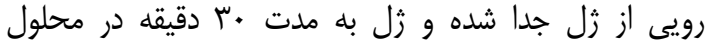

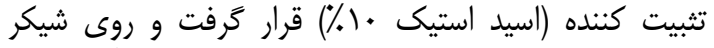

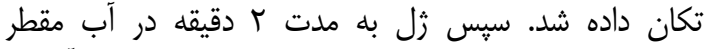

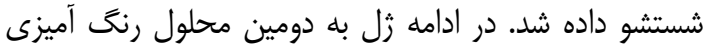

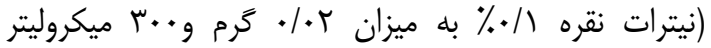

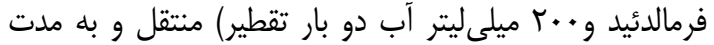

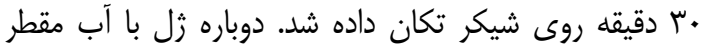

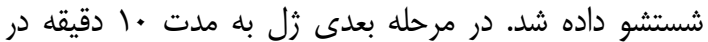

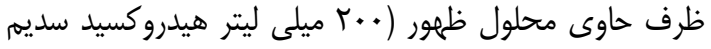

مشاهده محصول واكنش زنجيرهاي يليمراز

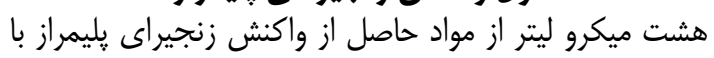

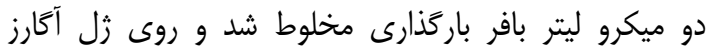

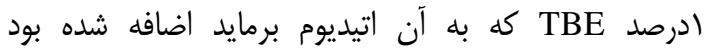

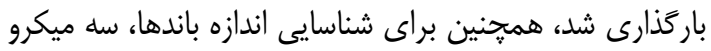

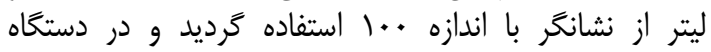

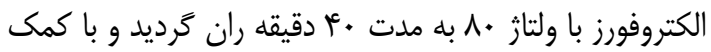

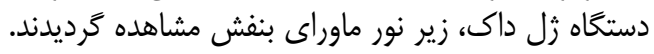
الكتروفورز با زل يلى اكريل ديل زئل آميد

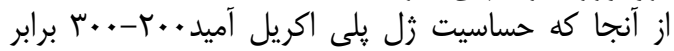

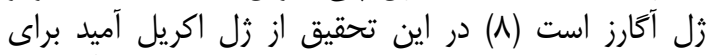

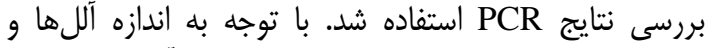

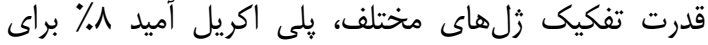

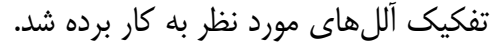
الكتروفورز كردن نمونهها و رنكَ آميزى

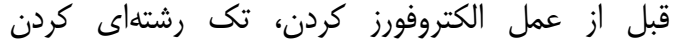

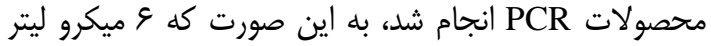
از محصول PCR را با • إ ميكروليتر از محلول واسرشته ساز

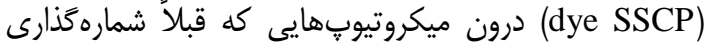


كه در اين مدلها

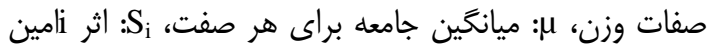
جنس حيوان (نر، ماده)،

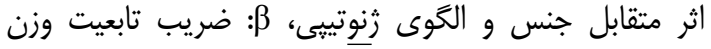

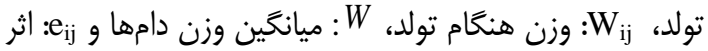

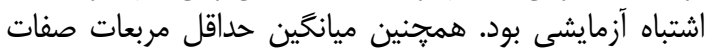
در سطح احتمال ه درصد تزارش شد.

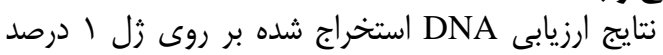

\section{نتايج و بحث}

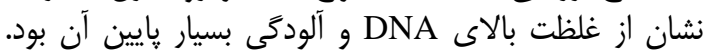

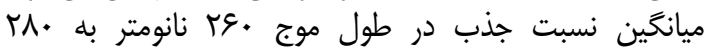
نانومتر برابر با ب بوديت

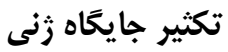

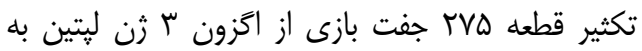

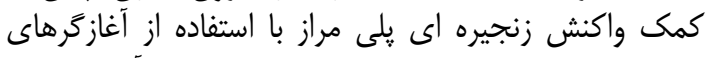

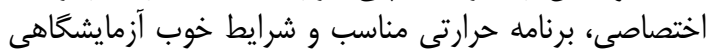
بدون قطعات غير اختصاصى به دست دست آمد.

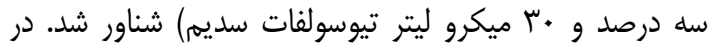

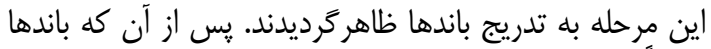

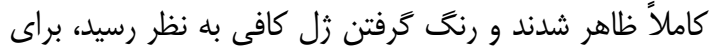

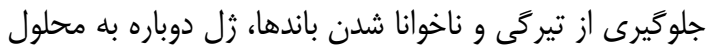

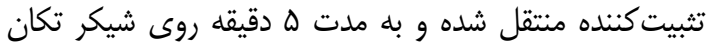

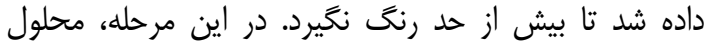

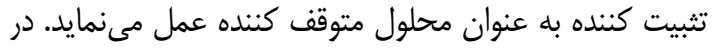

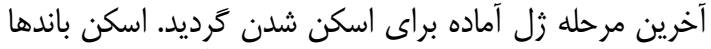

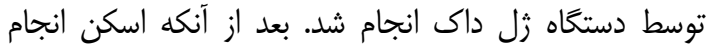

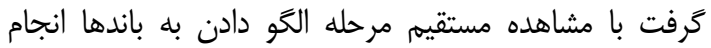

\section{تجزيل و تحليل دادههاى آمارى}

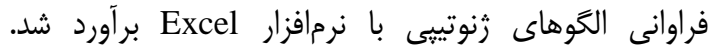

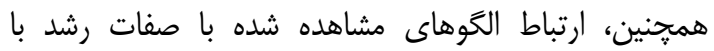

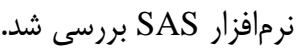
مدل بررسى ارتباط بين الخوهاى زنوتيبى و وزن تولد: $\mathrm{y}_{\mathrm{ij}}=\mu+\mathrm{S}_{\mathrm{i}}+\mathrm{G}_{\mathrm{j}}+\mathrm{SG}_{\mathrm{ij}}+\mathrm{e}_{\mathrm{ij}}$

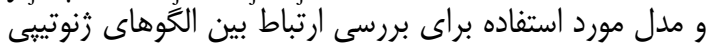

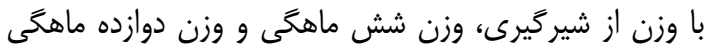

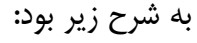

$\mathrm{y} \_\mathrm{ij}=\mu+\mathrm{s} \_\mathrm{i}+\mathrm{G}_{-} \mathrm{j}+\llbracket \mathrm{SG} \rrbracket \_\mathrm{ij}+\beta\left(\mathrm{W} \_\mathrm{ij}-\mathrm{W}\right)+\mathrm{e}_{-} \mathrm{ij}$

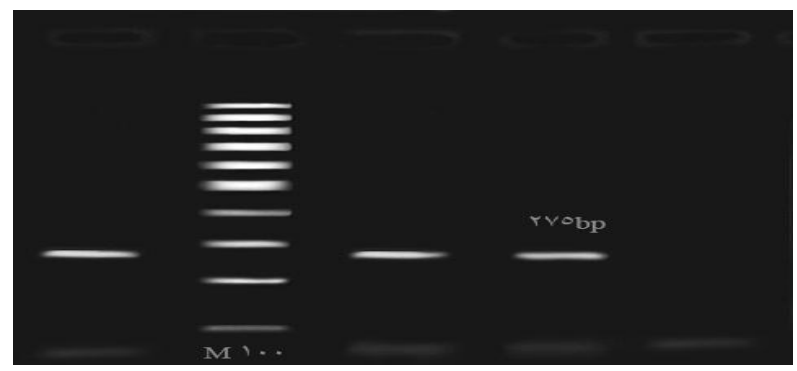

شكل I- محصول PCR قطعه PVD جفت بازى اكزون س ثن لِتين

Figure 1. PCR products (fragment 275bp) for Exon 3 of leptin gene

بر روى زل بلى اكريل آميد و رنحَ آميزى با استفاده از نيترات

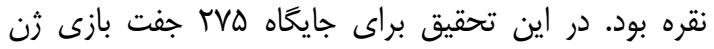

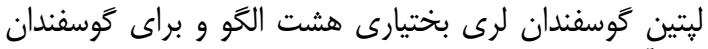

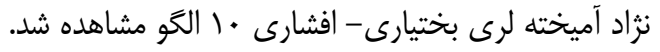

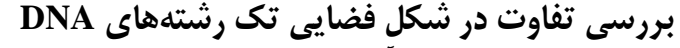

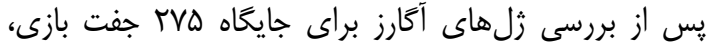

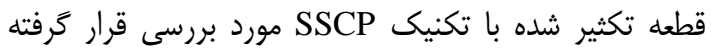
شد. اين روش شامل سه مرحله واسرشته سازى، الكتروفورز 


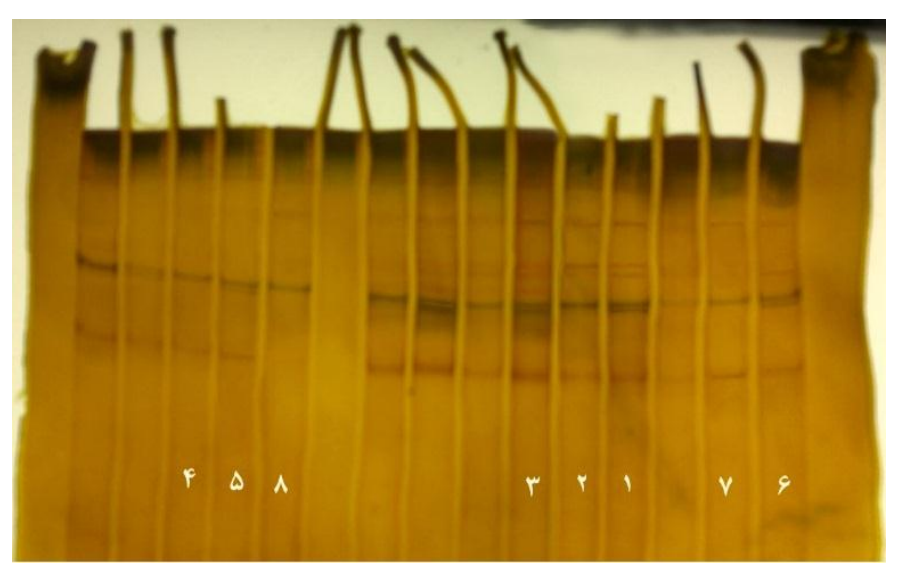

شكل r- يلى مورفيسم حاصل از تكنيك SSCP در رن لِتين گوسفند لرى بختيارى با هشت الخوى متفاوت

Figure 2. .SSCP polymorphism of Lori- Bakhtiari sheep in leptin gene with eight different patterns (genotype)

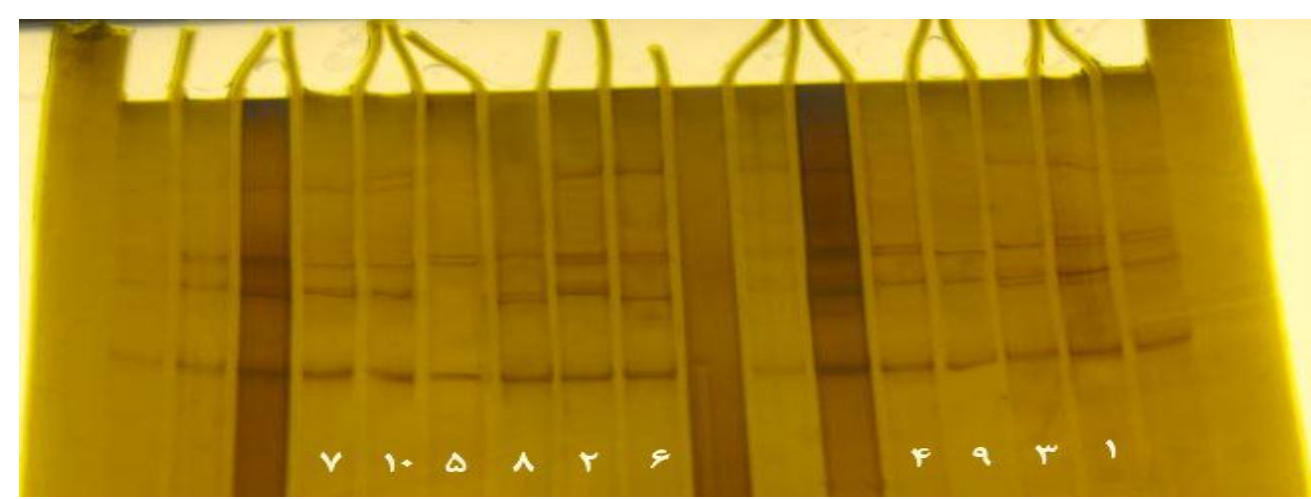

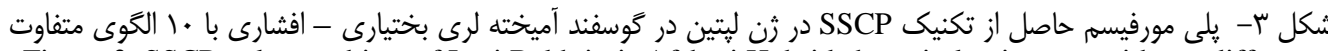
Figure 3. SSCP polymorphism of Lori Bakhtiari- Afshari Hybrid sheep in leptin gene with ten different patterns (genotype)

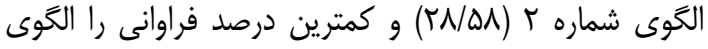

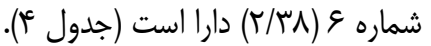
نتايج تجزيه و تحليل دادههاى آمارى

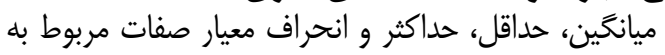

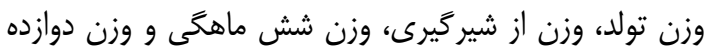

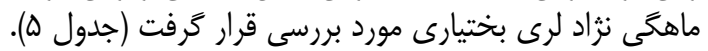

فراوانى الكوهاى زنوتيبى در كَوسفندان نزاد لرى لرى بختيارى و آميخته لرى بختى ونتيارى -افشارى

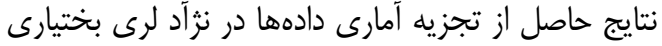

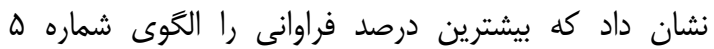

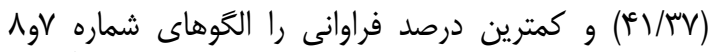

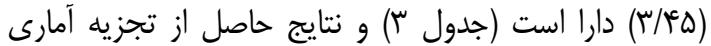

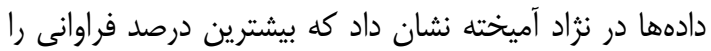

Table 3. Frequency of SSCP pattens leptin gene in Lori- Bakhtiari sheep

جدول س- فراوانى الخوهاى SSCP ثن ليتين در گوسفندان نزاد لرى بختيارى

\begin{tabular}{|c|c|c|c|c|c|c|c|c|c|}
\hline شماره الكَو & 1 & $r$ & $r$ & f & a & 9 & $v$ & 1 & كل \\
\hline فراوانى & 11 & 9 & $r$ & F & TY & 9 & $r$ & $r$ & $\Delta \Lambda$ \\
\hline درصد الكَوها & W/9V & $1 . / \% \Delta$ & $\Delta / / V$ & $8 / 19$ & $F / / r V$ & $1 . / \% \Delta$ & $r / \uparrow \Delta$ & $r / \uparrow Q$ & $1 .$. \\
\hline
\end{tabular}

جدول ع- فراوانى الخوهاى SSCP كوسفندان نثاد آميخته لرى بختيارى - افشارى Table 4. Frequency of SSCP pattens of leptin gene in Lori- Bakhtiari and Afshari Hybrid sheep

\begin{tabular}{|c|c|c|c|c|c|c|c|c|c|c|c|}
\hline شماره الكَو & 1 & r & r & r & $\Delta$ & 9 & v & $\wedge$ & 9 & 1. & كل \\
\hline فراوانى & r & ir & 1 & r & r & r & 9 & f & r & r & et \\
\hline درصد الخوها & Q/QT & $r N / \Delta \Lambda$ & $r / \mu \Lambda$ & $q / \Delta r$ & f/ve & $V / l f$ & $\mid F / T \Lambda$ & $q / \Delta r$ & Q/Dr & f/ve & $1 .$. \\
\hline
\end{tabular}


Table 5. Descreptive Statistics of Lori Bakhtiari sheep breed

\begin{tabular}{|c|c|c|c|c|c|c|c|}
\hline انحراف معيار & ميانگين & مجموع & حداكثر & حداقل & محدوده & تعداد دام & صفت \\
\hline$\cdot / \Lambda \&$ & $\Delta / 19$ & r99/V & $V / 9$ & $r / 9$ & $r / \kappa^{c}$ & $\Delta \Lambda$ & وزن تولد \\
\hline$f / v q$ & س س & $19 \Delta 8 / \Delta$ & $F T / D$ & $T r / \Lambda$ & $19 / 8$ & $\Delta \Lambda$ & وزن از شيرگيرى \\
\hline س & $\Delta T / G F$ & $r \cdot \Delta \Psi / \Delta$ & $V / \Delta$ & rt & $F \mid / D$ & $\Delta \Lambda$ & وزن شش ماهگى \\
\hline $\mid r / 9 \Lambda$ & $91 / \cdot 1$ & TrQ & $M$ & rN/D & $P q / \Delta$ & $\Delta \Lambda$ & وزن دوازده ماهگى \\
\hline
\end{tabular}

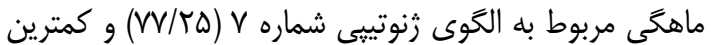

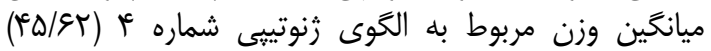

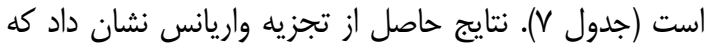

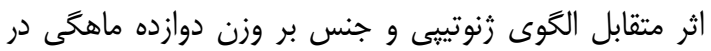

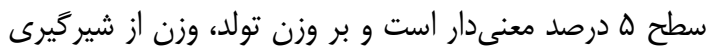

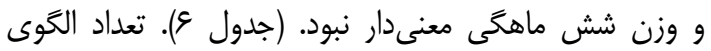

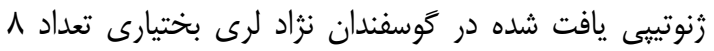

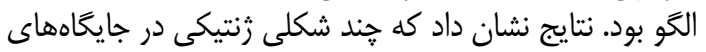
زنى لِيتين وجود دارد.
رابطه الكوهاى زنوتيبى و صفات مورد بررسى

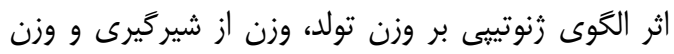

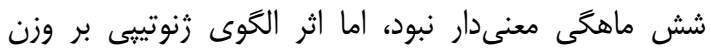

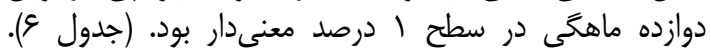

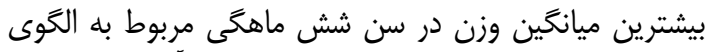

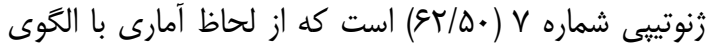

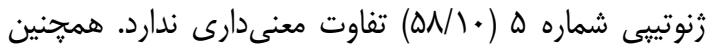

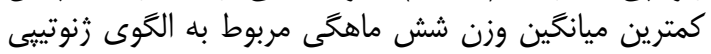

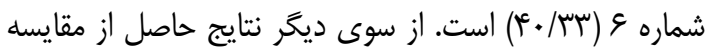

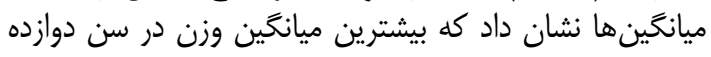

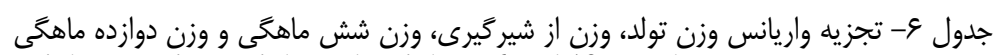
Table 6. Analysis of Variance for birth weight, weaning weight and weight at 6 and 12 months

\begin{tabular}{|c|c|c|c|c|c|c|c|c|c|}
\hline Sig & وزن دوازده ماهكى & Sig & وزن شش ماهكى & Sig & وزن از شيرگيرى & Sig & وزن تولد & درجه آزادى & منبع تغييرات \\
\hline$\cdot$ & N/Vq" & . & $I V / \cdot r$ & $\cdot 1 \cdot \mathrm{V}$ & $r / r q^{\text {IIs }}$ & $\cdot / \cdot 1$ & $\Gamma / \backslash Q^{\mathrm{nS}}$ & 1 & جنس \\
\hline r. & $r / 4 \varphi^{\prime \prime}$ &.$/ T \Lambda$ & $1 / T v^{\mathrm{ns}}$ &.$/ W V$ & $\cdot / \Delta v^{\mathrm{ns}}$ & .191 & $\cdot / r{ }^{\mathrm{ns}}$ & v & الخوى رنوتييى \\
\hline $.1 \cdot f^{c}$ & $r / 9 . "$ &.$/ 4 F$ & $\cdot / 90^{\mathrm{ns}}$ &.$/ \mathrm{AV}$ & $\cdot / r^{\mathrm{ns}}$ & .191 &.$/ q v^{\mathrm{ns}}$ & v & اثر متقابل \\
\hline
\end{tabular}

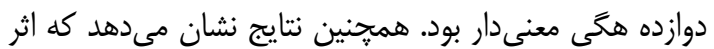

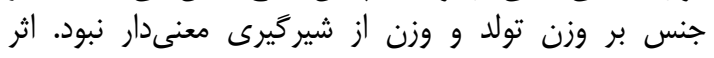

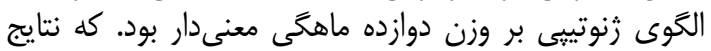

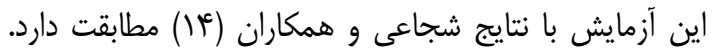

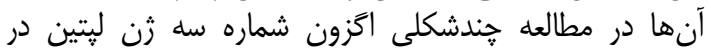

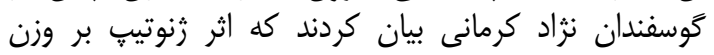

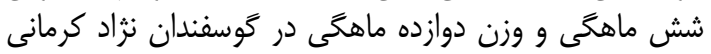

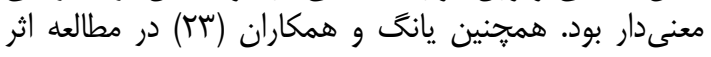

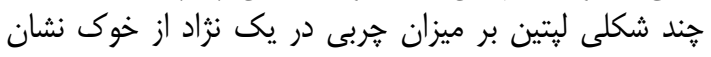

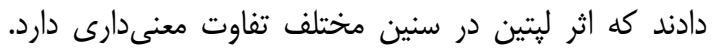

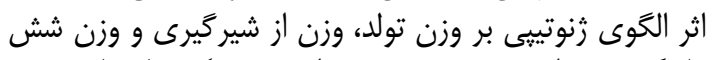

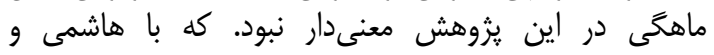

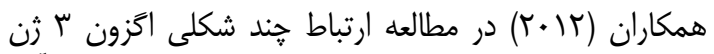

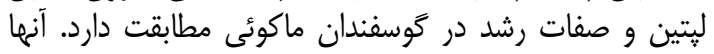

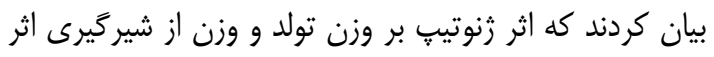

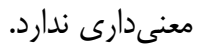

طهمورث يور و همكاران (19) در بررسى ثن ليتين در

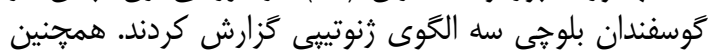
Zho

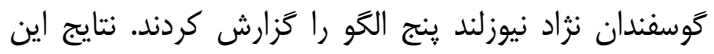

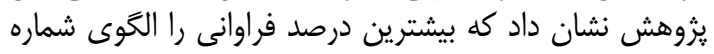

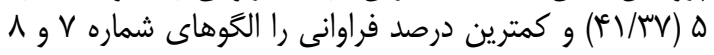

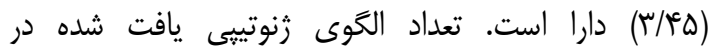

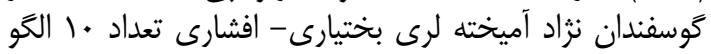

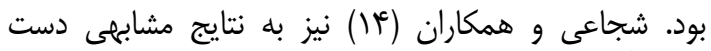

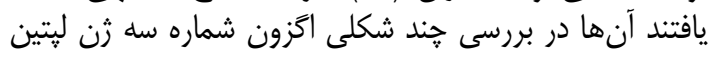

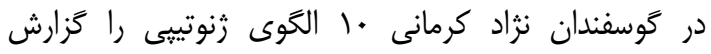

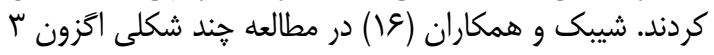

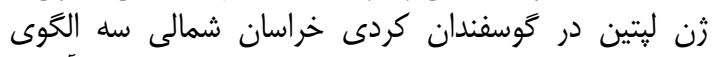

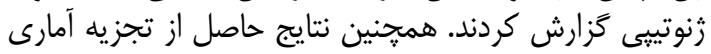

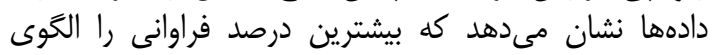

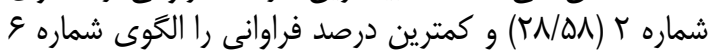

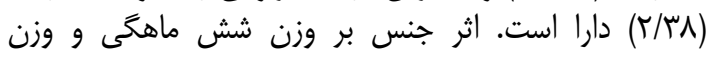

جدول V- مقايسه ميانگَين صفات وزن تولد، وزن از شير گيرى، وزن شش ماهكى و وزن دوازده ماهكى بين الخوهاى ثنوتيبى Table 7. Comparision of means for birth weight, weaning weight, weight at 6 and 12 months between genotypic patterns

\begin{tabular}{|c|c|c|c|c|}
\hline 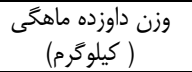 & 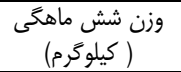 & 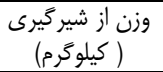 & 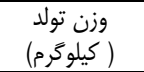 & الكَوى زنوتيبى \\
\hline 8$) / \mathrm{VV} \pm 1 / \mathrm{K}^{\mathrm{DC}}$ & $\Delta \omega / T r \pm \mid / \mu)^{a D}$ & $r Y / Q r \pm \Delta / q V$ & $\Delta / \mu^{\prime} \pm \cdot / \gamma^{c}$ & 1 \\
\hline$\Delta) / \Delta \Lambda \pm r / r)^{\text {cae }}$ & $\kappa \& / . . \pm r / \& \Lambda^{D C}$ & سז/T & $\Delta / \cdot 1 \pm \cdot / \Delta \phi$ & r \\
\hline$F \Delta / \& r \pm 1 / r^{\circ}$ & $r \cdot / v \Delta \pm \Delta / V r^{c}$ & سr/r & F/Or $\pm \cdot / V I$ & f \\
\hline \&N/G. $\pm 1.1 \cdot 1^{\mathrm{ad}}$ & $\Delta N / 1 \cdot \pm q / T \nabla^{a}$ & سr/Ar \pm & $\Delta / r V \pm 1 / \cdot r$ & $\Delta$ \\
\hline$\Delta r / \ldots \pm . / .^{\mathrm{ca}}$ & $\mathrm{r} \Delta / \ldots \pm . / \ldots{ }^{\mathrm{Dc}}$ & $\mathrm{m} / . . \pm . / .$. & $r / \Lambda) \pm . /$. & $\wedge$ \\
\hline
\end{tabular}


. Ahmadpanah, J. 2016. Phylogenetic analysis and molecular evolution of the leptin gene. Research on Animal Production, 7(13): 208-213.

2. Bahrenberg, G., I. Behrmann, A. Barthel and P. Hekerman. 2002. Indentifition of the critical sequence elements in the cytoplasmic domain of leptin receptor isoforms required for Janus kinas/ singal transducer and activator of transcription activation by receptor heterodimers. Molecular Endocrinology, 16(4): 859-872.

3. Boucher, D, M.F. Palin, F. Castonguay, C. Gariépy and F. Pothier. 2006. Detection of polymorphisms in the ovine leptine (LEP) gene: Association of a single nucleotide polymorphism with muscle growth and meat quality traits. Canadian Journal of Animal Science, 86: 31-35.

4. Buchanan, F.C., C.J. Fitzsimmons, A.G. Van Kessel, T.D. Thue, D.C. Winkelman Sim and S.M. Schmutz. 2002. Association of a missense mutation in the bovine Leptin gene with carcass fat content and leptin mRNA levels. Genetic Selection Evolution, 34: 105- 116.

5. Buchanan, F.C., V. kessel and A.G. Waldner. 2003. Hot topic. An association between A Leptin single polymorphism and milk and protein yield, Journal of Dairy Science, 86: 3164-3166.

6. Daridia, S., J. Williams, U. Bruggemand, M. Onagbesand, N. Raverc, E. Decuypred, J. Djianed, A. Gertlerc and M. Taouis. 2000. Achichen leptin -specific radio immunoassay. Domestic Animal Endocriology, 18: 325-335.

7. Friedman, J.M. and J.L. Halaas. 1998. Leptin and the regulation of body weight in mammals. Nature 395: 763-770.

8. Javanmard, A. 2001. Study the polymorphism of growth hormone receptor gene promotor (GHR) in Sistani cows. M.Sc. Dissertation in Animal Science. University of Tehran (In Persian).

9. Keshavarz, A. 2011. Study the polymorphism in Leptin gene in Najdi cows using PCR-RFLP teqnique. MSc Dissertation on Animal Science. Ramin University. 67 pp (In Persian).

10. Lagonigro, R.P., F. Wiener, J.A. Pilla and J. Woolliams. 2003. A new mutation in the coding region of the bovine Leptin gene associated with feed intake. Animal Genetics, 34(5): 371-374.

11. Liefers, S.C., M.F. Te Pas, R.F. Veerkamp, Y. Chilliard, C. Delavaud and R. Gerritsen. 2003. Association of Leptin gene polymorphisms with serum leptin concentration in dairy cows. Mammalian Genome, 14: 657-663.

12. Matarese, G., A. La Cava, V. Sanna, GM. Lord, R.I. Lechler and S. Fontana. 2002. Balancing susceptibility to infection and autoimmunity: a role for leptin. Trends in Immunology, 23:182-187.1

13. Schenkel, F.S., S.P. Miller, X.Ye.S. Moores, J.D. Nkrumah and C. Li. 2005. Association of single nucleotide polymorphisms in the leptin gene with carcass and meat quality traits of beef cattle. Journal of Animal Science, 83: 2009-2020.

14. Shojaei, M., M.R. Mohammadabadi, M. Asadi Fozi, K.A. Esmailizadeh, M.H. Ferdowsi, A. Torabi, M. Tayyarzadeh and H. Mirzakhani. 2010. Using PCR-SSCP technique to investigate polymorphism of Leptin gene in Kermani sheep. Animal Science Researches, 20: 115-122.

15. Solgi, H., A. Tohidi and M. Moeini. 2004. Relationship of Leptin concentration and FSH with lambing percent in Iranian sheep. Proceeding of First Congress on Animal Aquatic Science. University of Tehran. 31 August- 2 September (In Persian).

16. Shibak, A., B. Montazertorbati, H. Farhangfar, R. Ashkani Far. 2014. Study of genetic polymorphisms in exon 3 of the Leptin gene and its assosiation with birth weight and growth traits in North Khorasan Kurdi sheep. Modern Genetic, 4: 511-516 (In Persian).

17. Talebi, M.A., S.R. Miraei Ashtiani, M. Moradi Shahre Babak and A. Nejati Javaremi. 2010. Econimic values for reproduction, growth and carcass in Lori Bakhtiari Sheep. Animal Science Journal, 41(13) 203-213 (In Persian).

18. Tahmoorespoor, M., M.R. Nasiri, M. Ansari, A. Heravi and F. Eftekhar Shahroodi. 2008. Polymorphism of Leptin gene and its relationship with daily dain in Baloochi sheep. Proceeding of $3^{\text {th }}$ Congress on Animal Aquatic Science. University of Ferdoosi. Mashhad (In Persian).

19. Tahmures poor, M., M.R. Nassiry, M. Ansary, A. Heravi Mousavi, M. Vafaye vale and F. Eftekhar Shahroudi. 2009. Analysis of Leptin genepolymorphism and their association with average dailygain trait in Baluchi sheep. $3^{\text {rd }}$ Congress of animal science, Mashhad, Iran.

20. Taouis, M., J.W. Chen, C. Daviaud, J. Dupont, M. Derouet and J. Simon. 1998. Clonning the chiken Leptin gene. Gene, 208: 239-242.

21. Van der Lende, T., M.F. Te Pas, R.F. Veerkamp and S. Liefers. 2005. Leptin gene polymorphisms and their phenotypic associations. Vitamins and Hormones, 71: 373-404.

22. Vatan Khah, M., M. Moradi Shahr Babak, A. Nejati Javaremi, R. Vaez Torshizi and S.R. Miraei Ashtiani. 2005. Study the phenotypic and genetic characterizations for growth traits in Lori Bakhtiari lambs. Iranian Agricultural Science Journal, 36(6): 1455-1463 (In Persian).

23. Yang, D., H. Chen, H.X. Wang, Zh. Tian and L. Tang. 2007. Association of polymorphisms of leptin gene with body weight and body sizes indexes in Chinese indigenous cattle. Journal of Genetics and Genomics, 34(5): 400-405.

24. Zhang, Y., R. Proenca, M. Maffei, M. Barone, L. Leopold, J.M. Friedman.1994. Positional cloning of the mouse obese gene and its human homologue. Nature, 372: 425-432.

25. Zhou, H., J.G. Hickford and H. Gong. 2009. Identification of allelic polymorphism in the ovine leptin gene. Mol Biotechnology, 41: 22-25. 


\title{
Study of the Polymorphism of Leptin Gene and Its Association with some Growth Traits in Lori Bakhtiari and Lori Bakhtiari-Afshari Croessbreed Sheep
}

\section{Ali Ghazi Khani Shad and Mohammad Kazem Sharifi Shoorabi}

Department of Animal Science, Islamic Azad University, Saveh Branch, Saveh, Iran (Corresponding Author: alighazikhanishadd@ gmail.com)

Received: Nov 13, $2017 \quad$ Accepted: July 18, 2018

\begin{abstract}
The purpose of this study was evaluation of leptin gene polymorphism by PCR-SSCP and its relationship with some growth traits in Lori Bakhtiari and crossbred of Lori Bakhtiari- Afshari sheep. Blood samples were collected from 58 sheep (male and female) of Lori-Bakhtiari in Shahr-e-Kord Sholi station and 42 sheep (male and female) of Lori Bakhtiari-Afshari crossbreed from villages of Shahr-e-Kord. DNA was extracted, using extraction kit of Sinnagen co. Evaluation of quality and quantity of DNA was performed using agarose gel electrophoresis and spectrophotometry. Polymerase chain reaction (PCR) was conducted to amplify 275 bp fragment of exon 3 of leptin gene. Then single strand conformation polymorphism (SSCP) of PCR products was performed and genotypic patterns were obtained using acrylamid gel and silver staining. For leptin gene in Lori bakhtiari sheep, 8 band patterns including $\mathrm{L}_{1}$ to $\mathrm{L}_{8}$ and for crossbreeds sheep, 10 band patterns including $\mathrm{L}_{1}$ to $\mathrm{L} 10$ were obtained. There was a high polymorphism in exon 3 of the leptin gene in both breeds. Also results of means comparison showed that the leptin gene was significantly associated with weight at 6 and 12 months.
\end{abstract}

Keywords: Lori-Bakhtiari, Growth Traits, PCR-SSCP, Leptin, Polymorphism 